\title{
Caracterização de argilas e composição de massas cerâmicas preparadas com base na análise de curvas de consistência de misturas argila-água
}

\section{(Characterization of clays and ceramic mass compositions prepared on the basis of consistency curve analysis of clay-water mixtures)}

\author{
M. M.T. Moreno ${ }^{I}$, C. Del Roveri ${ }^{2}$, L. H. Godoy ${ }^{1}$, A. Zanardo ${ }^{I}$ \\ ${ }^{I}$ Instituto de Geociências e Ciências Exatas, Universidade Estadual Paulista, Av. 24-A, n. 1515, \\ Rio Claro, SP, 13506-900 \\ ${ }^{2}$ Instituto de Ciência e Tecnologia, Universidade Federal de Alfenas, Campus Avançado de Poços de Caldas, \\ $M G, 37715-400$ \\ mmoreno@rc.unesp.br,carolina.roveri@unifal-mg.edu.br,leticiahirata@gmail.com,azanardo@rc.unesp.br
}

\begin{abstract}
Resumo
Os produtos cerâmicos obtidos com argilas naturais são muito variados (tijolos, vasos, pisos) e a maioria das matériasprimas possui alto conteúdo de ferro, apresentando tons avermelhados, principalmente após queima. Esta pesquisa estudou argilas utilizadas por uma fábrica de blocos cerâmicos localizada no polo Tatuí-Sorocaba - SP. Na caracterização das mesmas, foram abordados aspectos físico-químicos, geoquímicos, mineralógicos e cerâmicos com o intuito de analisar sua influência na composição de massas, as quais foram formuladas e processadas em laboratório com base na análise da consistência de misturas argila-água. Este método se mostrou promissor para controle de qualidade, melhor aproveitamento dos materiais e alternativas para ajuste da proporção dos componentes de uma massa.

Palavras-chave: blocos cerâmicos, consistência de misturas argila-água, argila, aparelho Vicat Cone.
\end{abstract}

\begin{abstract}
Ceramic products made with natural clays are quite diverse (bricks, vases, tiles) and most of the raw materials have high content of iron, thus presenting reddish shades, especially after firing. This research studied clays from a ceramic block factory located in the Tatuí-Sorocaba ceramic region (S. Paulo, Brazil). The samples were characterized by physicochemical, geochemical, mineralogical and ceramic tests in order to evaluate their influence on the composition of masses, which were formulated and processed in the laboratory based on the consistency analysis of clay-water mixtures. This method proved to be a promising tool for quality control, better use of raw materials, and to identify the alternatives for adjusting the proportion of mass components.
\end{abstract}

Keywords: ceramic blocks, clay-water mixture consistency, clay, Vicat Cone apparatus.

\section{INTRODUÇÃO}

Durante a extração das matérias-primas dentro da área minerada, as rochas sedimentares argilosas apresentam variações devido a transformações decorrentes dos processos geológicos de sedimentação, diagênese, hidrotermalismo e intemperismo, o que resulta em estratos sobrepostos diferenciados quanto à plasticidade, textura, dureza, teor de carbonatos, refratariedade, fusibilidade e reologia [1]. Estas variações afetam o controle de qualidade dos produtos conforme as matérias-primas são extraídas; por outro lado, o material da base da frente de lavra é mais duro em relação à porção superior, devido à menor alteração intempérica da cimentação entre as partículas individuais. Assim, a mineralogia diferenciada dos estratos influencia a distribuição granulométrica obtida durante o processo de moagem, requerendo exploração e beneficiamento das matérias-primas adequados. Na região de Laranjal Paulista, Cesário Lange e Tatuí (Estado de S. Paulo) afloram sedimentos argilosos da Formação Tatuí, fonte de ótima matéria-prima para cerâmica vermelha, cujos processos de queima possibilitam reações de sinterização sem presença de fase líquida em torno de $900{ }^{\circ} \mathrm{C}$. A qualidade da matériaprima deu origem ao importante polo Tatuí-Sorocaba (Área 2, Fig. 1), no qual o controle dos produtos ainda é feito mediante conhecimentos empíricos misturando apenas argilas desta formação extraídas de diferentes localizações, ou com argilas de várzeas a fim de atingir a plasticidade e resistência adequadas à conformação e manipulação. Outro setor industrial que utiliza argilas com alto teor de ferro é o 
de pisos e revestimentos, no polo cerâmico Santa GertrudesCordeirópolis (Área 6, Fig. 1); neste caso, as características exigidas podem ser diferentes devido aos processos aplicados, tanto na preparação de massas quanto nas etapas seguintes, principalmente na queima. Normalmente são argilas illíticas menos alteradas por processos intempéricos, extraídas de níveis mais profundos da coluna estratigráfica da Formação Corumbataí. Estas argilas contêm quantidades apropriadas de elementos alcalinos que agem como fundentes durante as reações de sinterização que ocorrem normalmente acima de $1000{ }^{\circ} \mathrm{C}$.

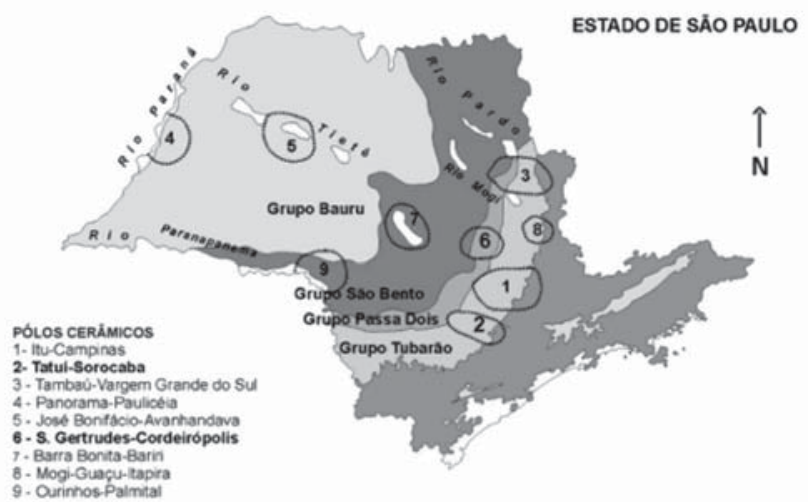

Figura 1: Polos de cerâmica vermelha e revestimentos no Estado de S. Paulo [2].

[Figure 1: Structural clay and tile ceramic regions in S. Paulo State [2].]

Para a conformação das peças é necessária uma interação argila-água para formar um filme líquido em volta das partículas de argila, cujo efeito lubrificante facilita o deslizamento entre as mesmas quando uma força é aplicada durante a conformação; assim, cada processo de fabricação necessita uma umidade que proporcione plasticidade e mobilidade suficiente às partículas. As propriedades desenvolvidas pelas argilas na presença de água incluem plasticidade, resistência mecânica a verde e seco, retração linear de secagem, compactação, tixotropia e viscosidade [1]. Quando submetidas ao processo de secagem e queima, as peças sofrem alterações de peso e volume, promovem alterações em ligações atômicas, aceleram a difusão de espécies atômicas, reduzem a porosidade e área específica e modificam as propriedades [3]. Durante o processo de queima realizado em torno de $900{ }^{\circ} \mathrm{C}$, a sinterização é dominada por mecanismos de difusão, os quais dependem de diversos fatores, entre eles tamanho, forma e empacotamento das partículas [4]; sendo assim, os principais elementos que contribuem para as transformações químicas durante os longos períodos de queima estão contidos nas estruturas das argilas illíticas e esmectíticas ou adsorvidas nas caulinitas (tais como complexos ferruginosos e íons de sais solúveis). Tendo em vista a complexidade das matérias-primas denominadas argilas, nesta pesquisa foram abordados diferentes aspectos que envolvem sua transformação em produtos cerâmicos, analisadas individualmente e misturadas em formulações de massas com base nas propriedades antes e após queima. As massas foram preparadas a partir de informações obtidas de gráficos de variação da consistência de misturas argila-água com o conteúdo de água das matérias-primas individuais.

\section{EXPERIMENTAL}

Seleção e coleta de amostras: os critérios para seleção de amostras foram baseados no grau de alteração, posição na frente de lavra, localização das minas e porção exposta da coluna estratigráfica. Foram amostradas 4 minas utilizadas por uma indústria da região onde se localiza o polo cerâmico Tatuí-Sorocaba: mina 1; mina 2; mina 3 e mina 4.

Processamento das amostras de argila: a secagem das amostras foi realizada a $60^{\circ} \mathrm{C}$ em estufa por $24 \mathrm{~h}$ e moagem em moinho de martelo para laboratório (Servitec), com peneira de abertura de 1,0 $\mathrm{mm}$ estabelecendo um limite de tamanho de grão, peneirando o pó em malha ASTM n ${ }^{\circ} 35$ (abertura de $0,5 \mathrm{~mm}$ ) para preparação de corpos de prova e para a determinação da distribuição granulométrica por difração a laser.

Composição química: a análise química dos elementos preponderantes, reportada na forma de óxidos [5], foi obtida em amostras de três minas (1), (2) e (3).

Mineralogia: a mineralogia principal foi obtida por difração de raios X (PANalytical, Empyrean - radiação $\mathrm{Cu}-\mathrm{K} \alpha$ ). As determinações foram feitas na amostra total e fração menor que $2 \mu \mathrm{m}$, esta obtida desagregando a amostra moída em água deionizada e posterior sedimentação da fração maior que $2 \mu \mathrm{m}$ segundo a Lei de Stokes [4]. A suspensão com a fração menor que $2 \mu \mathrm{m}$ foi centrifugada para eliminar o excesso de água, sendo depois depositada em lâminas de vidro (ficando as partículas com orientação preferencial), secas a temperatura ambiente e analisadas na forma natural, tratadas com etilenoglicol durante $48 \mathrm{~h} \mathrm{e}$ queimadas a $500{ }^{\circ} \mathrm{C}$.

Distribuição granulométrica: foi determinada em granulômetro por difração a laser (Malvern, Mastersizer 2000) utilizando $800 \mathrm{~mL}$ de água e uma quantidade de argila moída de acordo com os limites determinados pelo instrumento, defloculada com duas gotas de hexametafosfato de sódio (10\%) e 15 a $45 \mathrm{~s}$ de ultrassom, aplicado em etapas de $15 \mathrm{~s}$ observando a variação do sinal mostrada no equipamento.

Granulação e moldagem: a granulação foi realizada calculando previamente a quantidade de água necessária para obter $9 \%$ de umidade, sendo esta borrifada e misturada na amostra contida em uma bandeja e disposta sobre uma balança, sendo posteriormente condicionada em saco plástico com descanso de 24 h e com o mínimo de ar; os corpos de prova foram prensados em molde de $7 \mathrm{~cm} \mathrm{x} 2$ $\mathrm{cm}$, utilizando aproximadamente $19 \mathrm{~g}$ de massa, de maneira que o valor da densidade das peças verdes fosse próximo a $2,0 \mathrm{~g} \cdot \mathrm{cm}^{-3}$.

Queima: foram aplicados dois processos de queima usando um forno para laboratório com controle de temperatura (Maitec, FE50RP): a) $2 \mathrm{~h}$ na temperatura máxima quando queimado até $900{ }^{\circ} \mathrm{C}$; e b) 2 min na 
temperatura máxima de $1100{ }^{\circ} \mathrm{C}$.

Propriedades cerâmicas: foram medidas e/ou calculadas diversas propriedades cerâmicas (média de cinco corpos de prova): absorção de água (AA); retração linear de secagem (RLS) e queima (RLQ); tensão de ruptura à flexão (TRF); e densidade aparente (D) [6,7].

Consistência de misturas argila-água: medida com o aparelho de Vicat-Cone adaptado [8], onde a sonda é substituída por cone de $30^{\circ}$. Entretanto, o molde original para acomodação da argila é um tronco-cônico de $40 \mathrm{~mm}$ de profundidade e diâmetro de $70 \mathrm{~mm}$ no lado menor, sendo necessários $300 \mathrm{~g}$ de argila moída para cada ponto do gráfico. Neste estudo a análise é comparativa entre as amostras, motivo pelo qual foi substituído por cilindro de polipropileno de $3,6 \mathrm{~cm}$ de diâmetro interno e $3,0 \mathrm{~cm}$ de altura, uma vez que testes realizados previamente constataram que o deslocamento dos pontos em relação ao molde original não afeta significativamente uma análise comparativa. Para cada ponto da curva foram pesados 80,0 g de amostra moída, secos a $70{ }^{\circ} \mathrm{C}$ durante 24 h e misturados com auxílio da espátula, inicialmente com $25 \mathrm{~mL}$ de água (medidos com bureta de $25 \mathrm{~mL}$ ) e posteriormente com pequenas adições até a obtenção de uma massa moldável e homogênea, a qual foi transferida para o molde disposto sobre uma placa de vidro e compactada, procurando deixar a superfície uniforme e com o mínimo de vazios. A ponta do cone foi ajustada na altura da superfície da massa, e as leituras foram realizadas $30 \mathrm{~s}$ após a haste ser solta. As medidas foram repetidas na mesma amostra após virar o cilindro e reacomodar a massa (4 leituras). Os outros pontos foram feitos pesando novamente $80 \mathrm{~g}$ de amostra e aumentando o volume de água em $0,5,1$ ou $2 \mathrm{~mL}$, medidos com a bureta (o valor depende da composição e distribuição granulométrica

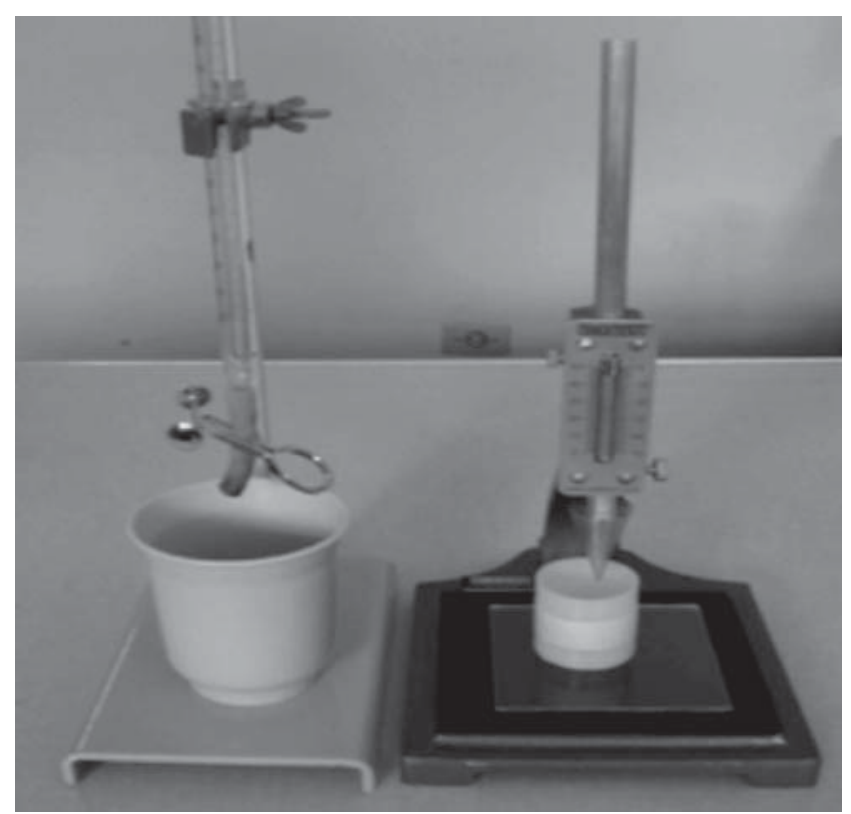

Figura 2: Aparelho de Vicat Cone utilizado nos ensaios. [Figure 2: Vicat Cone apparatus used in the tests.] da argila). Os gráficos de penetração do cone (mm) versus conteúdo de água em \% foram lançados no mesmo sistema de coordenadas, incluindo uma amostra de referência (neste estudo, uma massa cerâmica bem-sucedida na fábrica). A seguir, foi aplicada a regra de lever ou da alavanca [3] em etapas sucessivas até as matérias-primas selecionadas serem combinadas de forma a chegar a uma posição $\mathrm{x}$ igual ou muito próxima da massa de referência; para tanto foi selecionada uma profundidade fixa (coordenada y) e mediante as equações das retas foi calculada a coordenada $\mathrm{x}$ (\% de água).

\section{RESULTADOS E DISCUSSÃO}

Foram amostradas quatro minas no município de Cesário Lange, S. Paulo, levando em consideração as diferenças macroscópicas, resultantes de variações na estrutura, textura e coloração, atribuídas ao processo deposicional e à alteração intempérica. $\mathrm{O}$ material explorado nas minas faz parte do perfil de alteração, apresentando boa plasticidade, bandamento e laminações difusas ou localmente bem marcadas, textura síltico-argilosa e sem grandes variações nos pacotes extraídos para uso. As cores são variadas: amarelo, vermelho tijolo, verde pálido, creme, branco, cinza e matéria orgânica concentrada em pontos localizados de algumas minas, aparecendo como manchas pretas.

\section{Descrição das amostras}

Os ensaios realizados nas amostras coletadas foram orientados pelas observações no campo, por informações fornecidas pela indústria cerâmica, a experiência dos pesquisadores na área e os objetivos pretendidos. Os símbolos seguintes indicam os respectivos ensaios em cada amostra: análise química; - difratometria de raios $\mathrm{X}$; distribuição granulométrica de moagem; ensaios cerâmicos; e $\bullet$ ensaios de consistência:

- Fábrica - MF $(\bullet$ ): massa da fábrica coletada úmida na linha de produção;

- Mina 1: 1S_1 (•) e 1S_2 (•) - siltito arenoso de cor verde localizado na parte inferior da frente de lavra; 1B ( $\bullet$ ) - amostra maciça de cor esverdeada resultado da combinação de tons branco, verde e amarelo; 1M_1 ( $\bullet$ ) e 1M_2 (*) - porção intermediária da frente de lavra de cor vermelho-rosa com nível de matéria orgânica localizado no meio e na base do pacote, o qual apresenta continuidade horizontal, às vezes difusa; $1 \mathrm{~T}(\bullet)$ - nível branco do topo;

- Mina 2: 2B (•) - amostra da base da mina, de cor amarelo esverdeado, material não usado na fábrica; $2 \mathrm{M}(\bullet \bullet)$ - porção intermediária de cor amarelo mostarda; $2 \operatorname{Ar}(\bullet)$ nível de arenito com aproximadamente $40 \mathrm{~cm}$ de espessura, contendo carbonato e que corta o pacote intermediário; $2 \mathrm{~T}$ $(\bullet \bullet)$ - material do topo de cor avermelhada misturada com amarelo;

- Mina 3: 3B (•) - material amarelo esverdeado da

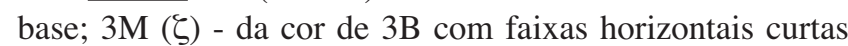
de cor marrom claro, contribui com $30 \%$ na composição da 
massa; 3T (• - amostra do topo de cor esbranquiçada com tons levemente amarelados;

- Mina 4: $\operatorname{Exp}(\bullet \vee)$ - argila dura de textura fina e cor cinza escuro; 4B $(\bullet)$ - amostra coletada na porção inferior da frente de lavra; $4 \mathrm{M}(\bullet)$ - amostra do meio com aspecto semelhante a $4 \mathrm{~B}$, na qual se destacam os tons cinza e amarelo; 4T1(•) e 4T2(•) - amostras do topo de cor cinza sendo T1 mais dura e localizada abaixo de T2.

\section{Caracterização química}

A Tabela I mostra os resultados da análise química dos elementos preponderantes, na forma de óxidos, das três minas principais, sendo a primeira (1) a mais importante na composição da massa usada na fábrica. Em função disso, foram analisadas duas amostras da porção intermediária retiradas de lugares distantes para avaliar a sua variação na direção horizontal. As amostras 1_S1 e 1_S2 estão localizadas na porção inferior aos níveis explorados, portanto, não eram utilizadas no processo cerâmico, assim como o material logo acima (1_B) de textura maciça e cores branco, esverdeado e verde amarelado, para as quais a difração de raios $\mathrm{X}$ mostrou que a amostra branca consiste basicamente de caulinita e quartzo (a illita já foi transformada em caulinita) e as outras duas de illita, caulinita e quartzo. O material da base da mina 2 também não era considerado apropriado por ser duro, lavrando somente o pacote intermediário e superior, sendo que entre estes dois níveis há um estrato arenoso (amostra 2 Ar) medindo em torno de $60 \mathrm{~cm}$ de espessura. Na mina 3, o nível intermediário (amostra 3 M) constituía 30\% na formulação da massa, com textura mais grossa contribuindo para limitar a retração das peças queimadas. A argila da mina 4 era usada na mistura com o rejeito das peças queimadas e incorporada na formulação da massa, sendo que o material da porção basal desta mina tem as mesmas características que o material estudado por [9] para obtenção de argila expandida, indicando que nesse ponto pode haver contato com a base da
Formação Corumbataí.

Para uma melhor visualização das variações dos principais elementos químicos entre amostras, foi calculada a proporção catiônica (ou atômica) e a porcentagem catiônica das mesmas [10], a qual permite uma análise do conteúdo efetivo dos cátions. Os gráficos para esta análise são apresentados na Fig. 3. A Fig. 3-I mostra a variação da proporção catiônica total de cada amostra, podendo ser observada pouca variação entre as três minas, exceto para as amostras 1_S1 e 1_S2 nas quais os teores de Ca e Na são relativamente altos devido a um estágio evolutivo menor que as amostras dos estratos superiores. As Figs. 3-II e 3-III mostram a variação da concentração dos elementos nas amostras, em porcentagem catiônica. A partir destes é possível verificar que os terrores de $(\mathrm{Fe}+\mathrm{Mg}), \mathrm{K}$ e $\mathrm{Al}$ sofreram evolução semelhante nos perfis (Figs. 3-IV e 3-V), sugerindo alterações causadas simultaneamente por processos geológicos durante a formação e transformação dos argilominerais; dessa forma, a perda ao fogo (L.O.I., loss on ignition) acompanha a variação da concentração do $\mathrm{Al}$, uma vez que as principais perdas durante a queima correspondem à água formada durante a desestruturação dos grupos - $\mathrm{OH}$ dos argilominerais (Fig. 3-V). A Fig. 3-VI mostra a variação do Si e da soma da porcentagem cationica de $(\mathrm{Al}+\mathrm{Fe}+\mathrm{Ti}+\mathrm{K})$, as quais mostram comportamento inverso, devido às reações de hidrólise que transformaram feldspatos e argilominerais tendendo a concentrar, nos níveis superiores, espécies químicas mais resistentes como quartzo e caulinitas.

$\mathrm{Na}$ fabricação de produtos de cerâmica estrutural, são utilizadas argilas mais alteradas, do ponto de vista de intemperismo físico-químico, que na indústria de pisos e revestimentos. Na Fig. 4, é feita a comparação entre amostras das duas Formações, Tatuí e Corumbataí, usadas nos dois segmentos industriais (Fig. 1, áreas 2 e 6) com base na perda ao fogo e a soma da proporção catiônica, mostrando que a análise química pode dar informações sobre as características básicas que distinguem as duas aplicações. À esquerda da

Tabela I - Análise química de amostras das minas 1,2 e 3 na região estudada. A sequência de siglas na nomenclatura corresponde à posição na frente de lavra: $\mathrm{S}=$ sub-base; $\mathrm{B}=$ base; $\mathrm{M}=$ meio; $\mathrm{T}=$ topo.

[Table I - Chemical analysis of samples from the mines 1, 2 and 3 in the studied region. The sequence of abbreviations in the nomenclature corresponds to the position within the mine: $S=$ sub-base; $B=$ base; $M=$ middle; $T=$ top.]

\begin{tabular}{llllllllllll}
\hline Am. & $\begin{array}{l}\mathrm{SiO}_{2} \\
(\%)\end{array}$ & $\begin{array}{l}\mathrm{TiO}_{2} \\
(\%)\end{array}$ & $\begin{array}{l}\mathrm{Al}_{2} \mathrm{O}_{3} \\
(\%)\end{array}$ & $\begin{array}{l}\mathrm{Fe}_{2} \mathrm{O}_{3} \\
(\%)\end{array}$ & $\begin{array}{l}\mathrm{K}_{2} \mathrm{O} \\
(\%)\end{array}$ & $\begin{array}{l}\mathrm{Na}_{2} \mathrm{O} \\
(\%)\end{array}$ & $\begin{array}{l}\mathrm{CaO} \\
(\%)\end{array}$ & $\begin{array}{l}\mathrm{MgO} \\
(\%)\end{array}$ & $\begin{array}{l}\mathrm{MnO} \\
(\%)\end{array}$ & $\begin{array}{l}\mathrm{P}_{2} \mathrm{O}_{5} \\
(\%)\end{array}$ & $\begin{array}{l}\mathrm{L} . \mathrm{O} . \mathrm{I} \\
(\%)\end{array}$ \\
\hline 1_S1 & 71,33 & 0,52 & 12,29 & 4,00 & 2,90 & 2,56 & 0,77 & 1,28 & 0,02 & 0,27 & 3,9 \\
1_S2 & 68,65 & 0,55 & 13,35 & 4,57 & 3,37 & 2,42 & 0,77 & 1,59 & 0,03 & 0,27 & 4,3 \\
1_B & 63,27 & 0,59 & 19,35 & 3,62 & 2,00 & 0,16 & 0,18 & 0,72 & 0,09 & 0,02 & 9,8 \\
1_M1 & 75,41 & 0,42 & 12,64 & 1,89 & 1,83 & 0,11 & 0,02 & 0,52 & 0,43 & 0,03 & 6,5 \\
1_M2 & 69,90 & 0,62 & 14,77 & 3,19 & 2,50 & 0,10 & 0,02 & 0,88 & 0,12 & 0,02 & 7,7 \\
2_M & 64,82 & 0,67 & 16,45 & 4,39 & 2,74 & 0,08 & 0,06 & 1,27 & 0,01 & 0,12 & 9,2 \\
2_T & 70,91 & 0,59 & 13,71 & 4,11 & 1,86 & 0,06 & 0,01 & 0,87 & 0,02 & 0,13 & 7,6 \\
3_M & 63,17 & 0,55 & 14,99 & 4,17 & 2,60 & 0,07 & 0,25 & 2,13 & 0,03 & 0,03 & 11,8 \\
3_T & 74,58 & 0,39 & 11,11 & 4,27 & 0,44 & 0,04 & 0,02 & 0,38 & 0,20 & 0,03 & 8,4 \\
\hline L_OI. perda aofogo & & & & & & & & & & &
\end{tabular}


Fig. 4 localizam-se as amostras das minas estudadas neste trabalho e mais alteradas, as quais apresentam menor valor da soma da proporção catiônica dos elementos preponderantes devido a perdas por processos de intemperismo, e à direita amostras da Formação Corumbataí menos alteradas, em princípio mais apropriadas como matéria-prima para pisos e revestimentos via seca, nas condições atuais de fabricação. Neste grupo estão as duas amostras da Formação Tatuí 1_ $\mathrm{S} 1$ e 1_S2, cujo conteúdo de $\mathrm{Na}_{2} \mathrm{O}$ é alto (Tabela I) e que
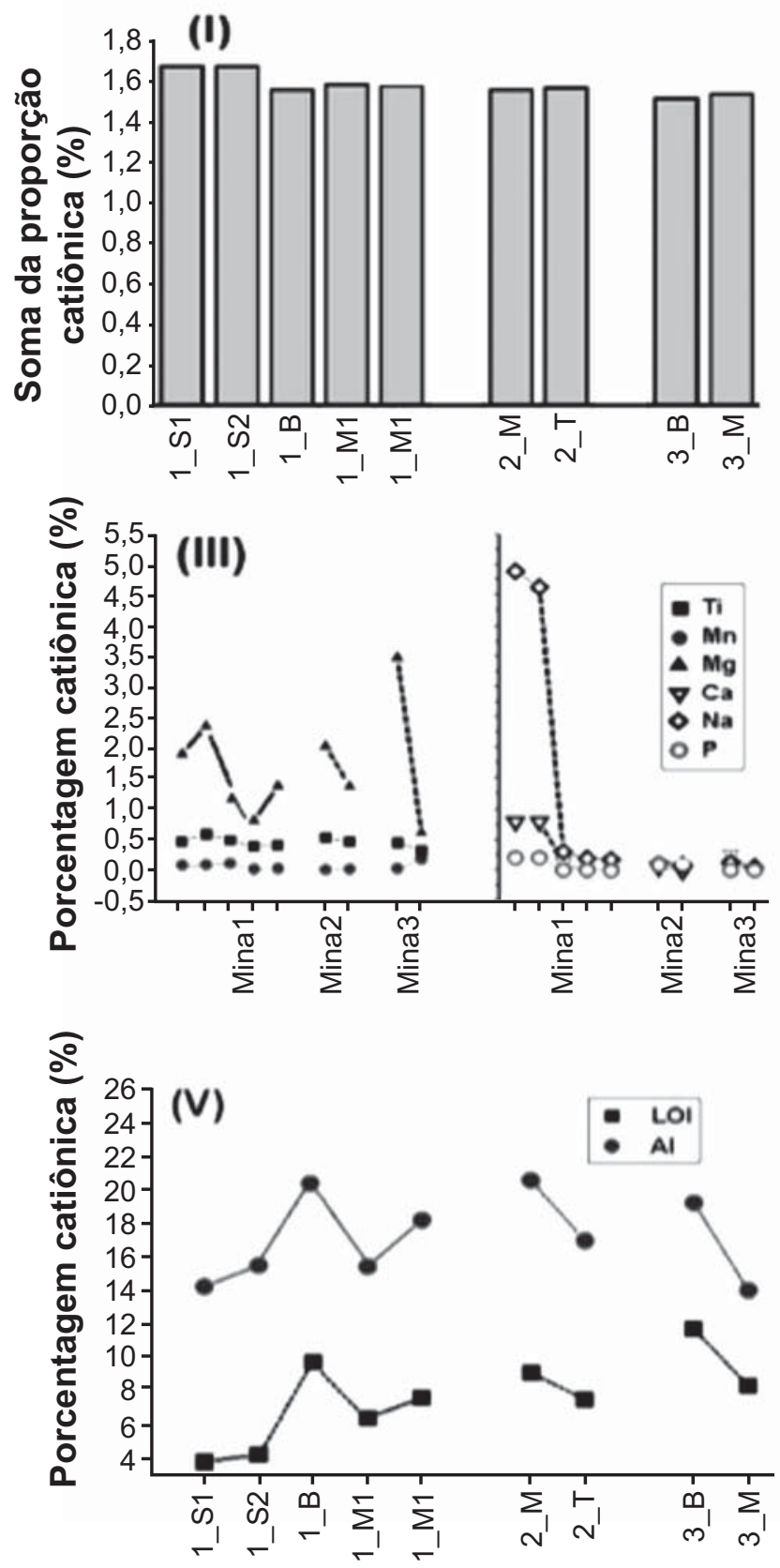

constituem um material não utilizado pela fábrica; por outro lado, as amostras da Formação Corumbataí localizadas no agrupamento de pontos à esquerda do gráfico correspondem a níveis da porção superior das frentes de lavra [11].

\section{Mineralogia}

As Figs. 5 e 6 mostram os difratogramas das amostras na sequência base-topo da mina, os quais mostram variações
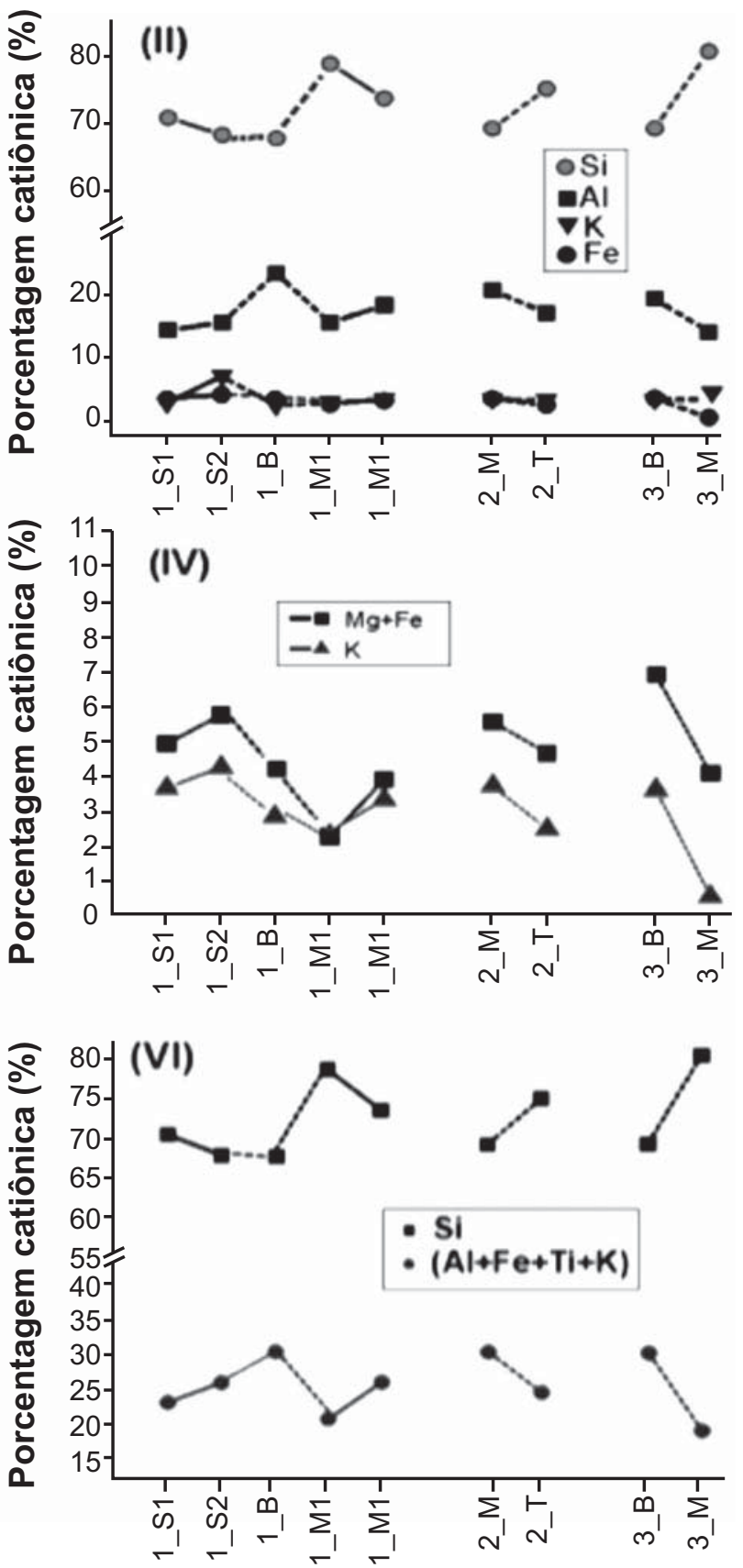

Figura 3: Análise dos elementos preponderantes em amostras das minas 1, 2 e 3: (I) somatória da proporção catiônica em amostras de cada perfil; (II e III) variação da concentração dos elementos no perfil de cada mina; (IV, V e VI) análise comparativa da concentração em cada perfil.

[Figure 3: Major elements analysis in the samples from mines 1,2 and 3: (I) sum of cationic proportion in the samples of each profile; (II and III) variation of element concentration in each mine profile; (IV, V and VI) comparative analysis of the concentration in each profile.] 


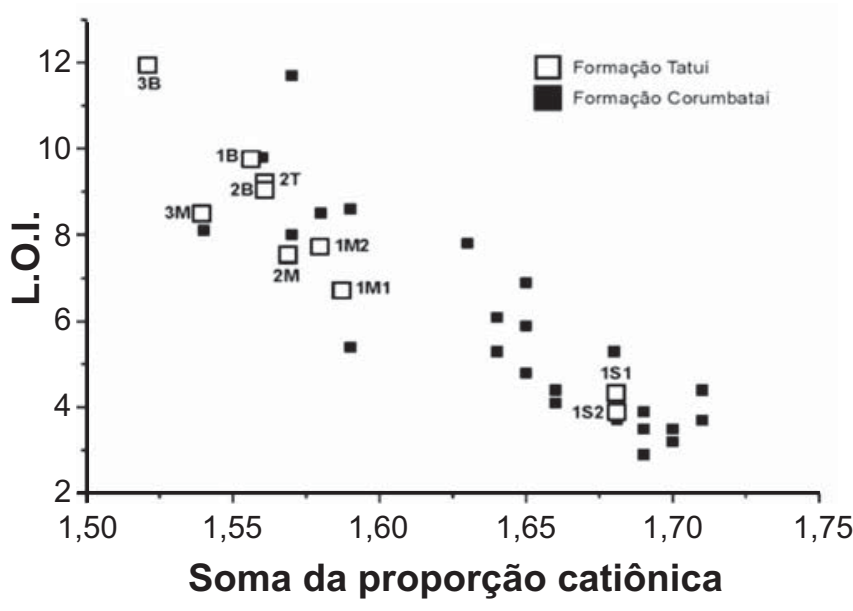

Figura 4: Perda ao fogo (L.O.I.) versus soma da proporção catiônica de argilas da Formação Tatuí usadas para obter blocos estruturais e da Formação Corumbataí usadas para pisos e revestimentos.

[Figure 4: Loss on ignition (L.O.I.) vs. sum of cationic proportion of clays from Tatuí Formation used for structural bricks and from Corumbataí Formation used for tiles.]

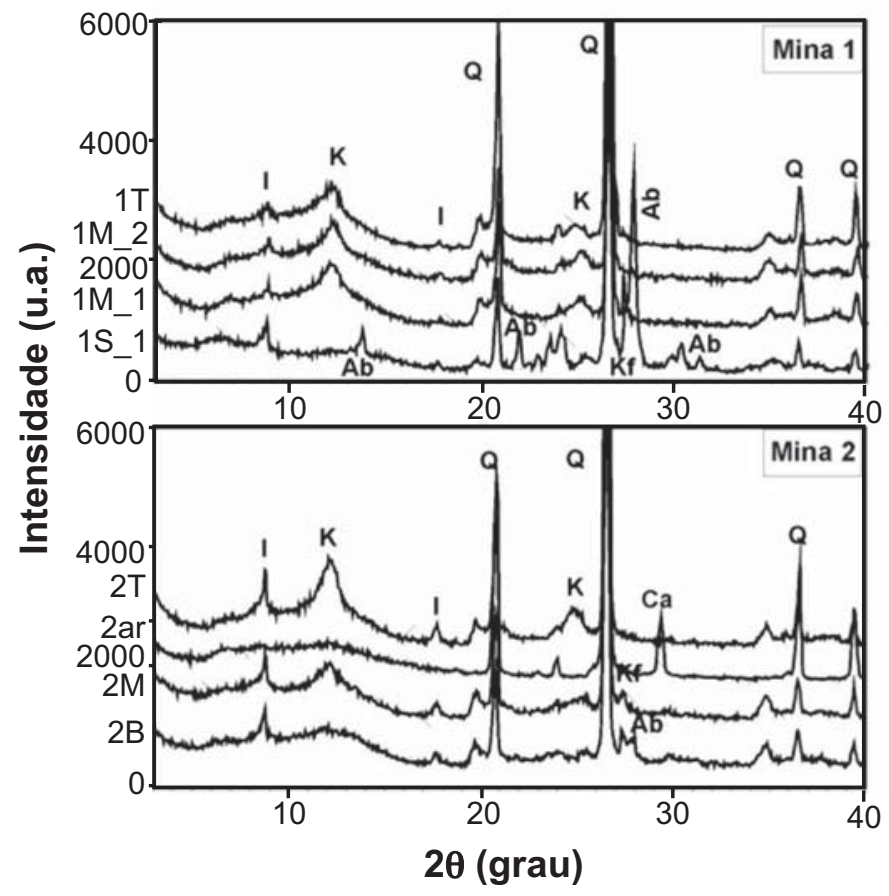

Figura 5: Difratograma de raios $\mathrm{X}$ (amostra total) dos perfis das minas 1 e 2. Minerais: $\mathrm{I}=$ Illita; $\mathrm{K}=$ caulinita; $\mathrm{Q}=$ quartzo; $\mathrm{Kf}=$ feldspato potássico; $\mathrm{Ab}=$ albita; $\mathrm{Ca}=$ calcita. Posição dos estratos: $\mathrm{S}=$ inferior à base da mina $1 ; \mathrm{B}=$ base; $\mathrm{M}=$ meio; $\mathrm{T}=$ topo $; \mathrm{Ar}=$ nível de arenito.

[Figure 5: X-ray diffraction patterns (full sample) of the mine profiles 1 and 2. Minerals: $I=$ illite; $K=$ kaolinite; $Q=$ quartz; $K f=$ potassium feldspar; $A b=$ albite $; C a=$ calcite. Position of the strata: $S=$ mine 1 sub-base $B=$ base $; M=$ middle $;=$ top $; A r=$ sandstone level.]

mineralógicas, principalmente quanto à proporção dos mesmos, sendo que em todos os casos é observada a presença de argilominerais com a base dos picos larga, pontas bifurcadas,

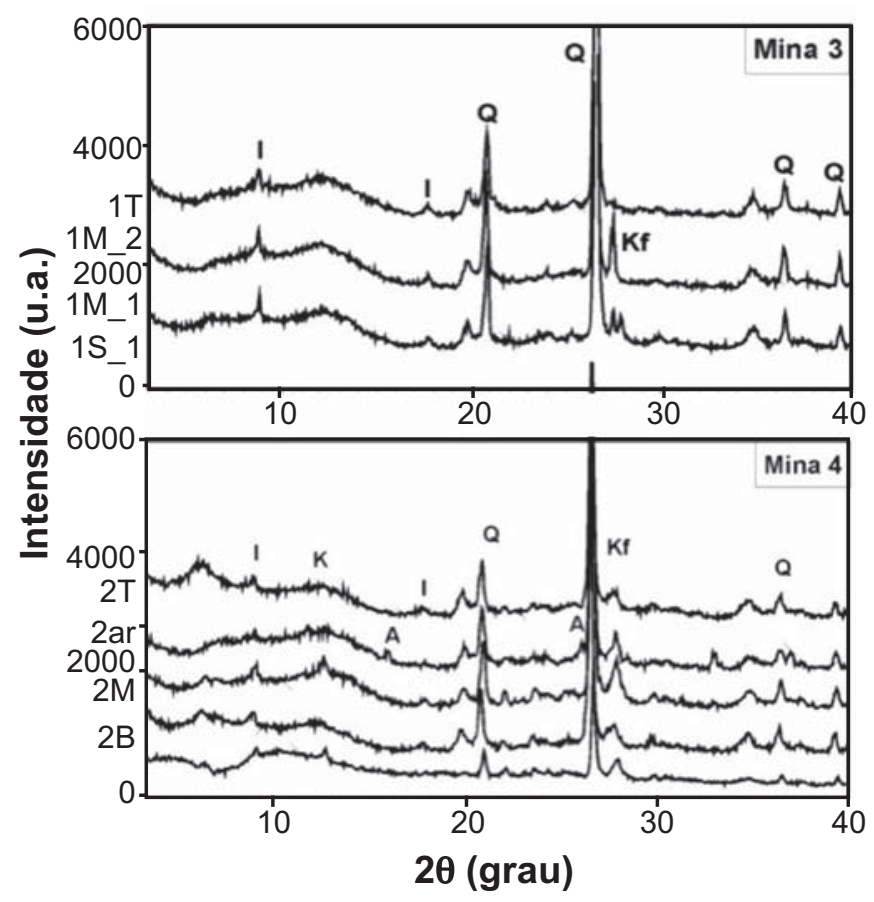

Figura 6: Difratograma de raios $X$ (amostra total) dos perfis das minas 3 e 4. Minerais: $\mathrm{I}=$ Illita; $\mathrm{K}=$ caulinita; $\mathrm{Q}=$ quartzo; $\mathrm{Kf}=$ feldspato potássico; $\mathrm{A}=$ analcima. Posição dos estratos: $\mathrm{B}=$ base; $\mathrm{M}=$ meio; $\mathrm{T}=$ topo; $\mathrm{Exp}=$ material inferior à base da mina 4.

[Figure 6: X-ray diffraction patterns (fulll sample) of mine profiles 3 and 4. Minerals: $I=$ illite; $K=$ kaolinite; $Q=$ quartz; $K f=$ potassium feldspar; $A=$ analcime. Position of the strata: $B=$ Base; $M=$ middle $; T=$ top $;$ Exp = mine 4 sub-base.]

assimetria e irregularidades no formato. A difração de raios X mostrou que a principal variação lateral nas amostras 1_M está no teor de feldspato potássico (Kf). Este mineral ocorre em maior proporção em 1_M1, enquanto 1_M2 apresenta melhor cristalinidade da caulinita (pico mais estreito e definido). A caulinita ocorre em todas as minas e é gerada a partir da alteração supérgena dos feldspatos e da illita, a qual remove parte dos elementos fundentes aumentando a refratariedade, porém possibilita a desagregação do material, a diminuição da granulometria e o aumento da plasticidade, aspecto essencial para a conformação do material e para as reações de sinterização. Com exceção dos estratos 1_S1, 1_S2 e 2_Ar, em todas as amostras foram identificados illita (I), caulinita $(\mathrm{K})$ e quartzo $(\mathrm{Q})$ em diferentes concentrações. Nas amostras do topo, os picos de feldspatos (Ab e Kf) são pequenos ou não aparecem, devido à alteração por exposição mais intensa aos agentes de intemperismo. Nos níveis menos expostos, ainda pode aparecer feldspato sódico além do potássico, este último mais resistente às alterações. O material da mina 4 (Fig. 6) é utilizado junto com resíduos de peças queimadas para limitar a retração das peças, evitando o aparecimento de trincas durante a secagem e queima das peças. Esta mina apresenta uma mineralogia mais variada que as outras, pois, além dos minerais comuns, contém analcima (mineral semelhante a albita, porém, hidratado) e o mineral gipsita $\left(\mathrm{CaSO}_{4} \cdot 2 \mathrm{H}_{2} \mathrm{O}\right)$ nas proximidades da frente de lavra. Nesta mina, o feldspato potássico permanece até o topo configurando uma menor 
alteração intempérica neste perfil e justificando seu uso como estruturante. As amostras 1_S1 e 1S_2 contêm significativa concentração de albita, o que está de acordo com o valor de sódio mostrado na análise química $\left(\sim 2,5 \%\right.$ de $\left.\mathrm{Na}_{2} \mathrm{O}\right)$. Este material pode ter aplicação em outro setor cerâmico, onde seja necessário incorporar fundentes à massa, desde que devidamente estudado para controlar as limitações, tais como conteúdo de carbonato, matéria orgânica, quartzo, tamanho das partículas de carbonato, entre outras.

A Fig. 7 mostra uma análise por difração de raios $\mathrm{X}$ da fração granulométrica $\Phi<2 \mu \mathrm{m}$ dos níveis intermediários das minas 1, 2 e 3, as mais utilizadas para formulação da massa. É possível observar que nessas matérias-primas, usadas para blocos estruturais, dominam os argilominerais illíticos e cauliníticos mal cristalizados, sendo que para estes a organização dos átomos na direção do espaçamento $\mathrm{d}_{\mathrm{hkl}}=3,5 \AA\left(2 \theta \sim 25^{\circ}\right)$ melhora quando a amostra é tratada com etilenoglicol. Não aparecem argilominerais expansíveis definidos como esmectitas ou estratificações regulares. As estratificações irregulares expansivas são pouco abundantes, aparecendo principalmente na mina 1 (amostra 1_M1), onde o pico da illita fica aumentado na amostra queimada após a perda da água entre as camadas da estrutura cristalina, sendo a amostra $3 \mathrm{M}$ a que apresenta menor quantidade destas estruturas irregulares.

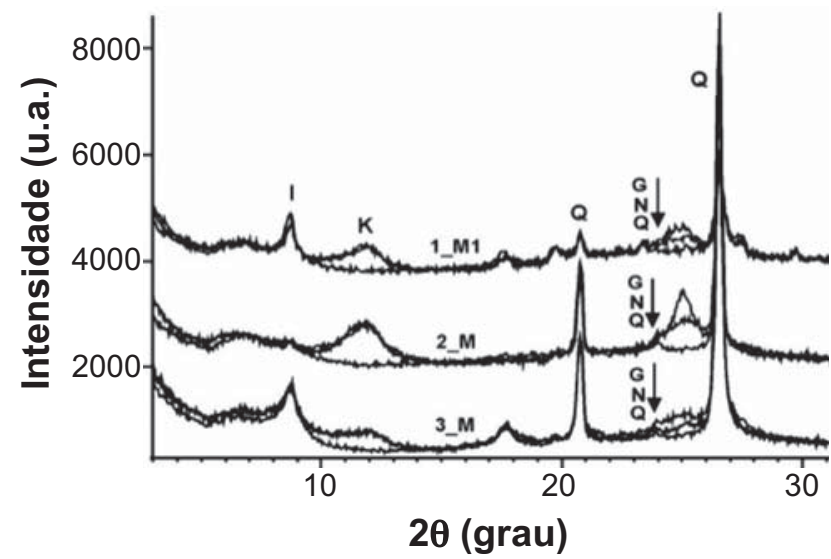

Figura 7: Difratograma de raios X da fração granulométrica $\Phi<2 \mu \mathrm{m}$ (na forma natural, tratada com etilenoglicol e queimada a $500{ }^{\circ} \mathrm{C}$ ) da porção intermediaria de três minas que representam os estratos mais utilizados. Minerais: $\mathrm{I}=$ illita; $\mathrm{K}=$ caulinita; $\mathrm{Q}=$ quartzo.

[Figure 7: X-ray diffraction patterns of the granulometric fraction $\Phi<2 \mu \mathrm{m}$ (in natural form, treated with ethylene glycol, and fired at $500{ }^{\circ} \mathrm{C}$ ) of the intermediate portion from the three mines, which represent the most used strata. Minerals: $I=$ illite; $K=$ kaolinite; $Q$ = quartz.]

\section{Distribuição de tamanho de partícula}

Foi determinada a distribuição granulométrica de moagem (Fig. 8) visando analisar o comportamento de queima apresentado com o empacotamento adquirido durante a confecção dos corpos de prova. É possível notar que a amostra Exp, localizada na base da mina 4 apresenta uma distribuição granulométrica de moagem gaussiana dentro da fração silte (escala ABNT), contribuindo com partículas de tamanho médio no empacotamento das misturas e com distribuição granulométrica semelhante a MF (massa da fábrica), esta com maior proporção de partículas maiores. MF não representa a massa da fábrica quanto a distribuição granulométrica, apesar de ter sido coletada na linha de produção, uma vez que, por estar úmida foi reprocessada em laboratório nas mesmas condições que as amostras coletadas em campo, o que afetou a distribuição granulométrica original. Uma distribuição próxima a estas duas amostras é apresentada por 2_T aparecendo quase juntas no gráfico de volume acumulado (passante); por outro lado, a amostra 3_T apresenta maior volume de partículas na fração maior que $62 \mu \mathrm{m}$ e está localizada no topo da mina. As amostras restantes (1_M1, 1_M2, 2_M e 3_M) pertencem à porção intermediária apresentando assim uma maior similaridade entre elas e aparecendo como um agrupamento no gráfico acumulado. Estes estratos são os principais componentes das massas e as outras matérias-primas têm a função de proporcionar condições de processamento e aprimorar as características desejadas para o produto final.

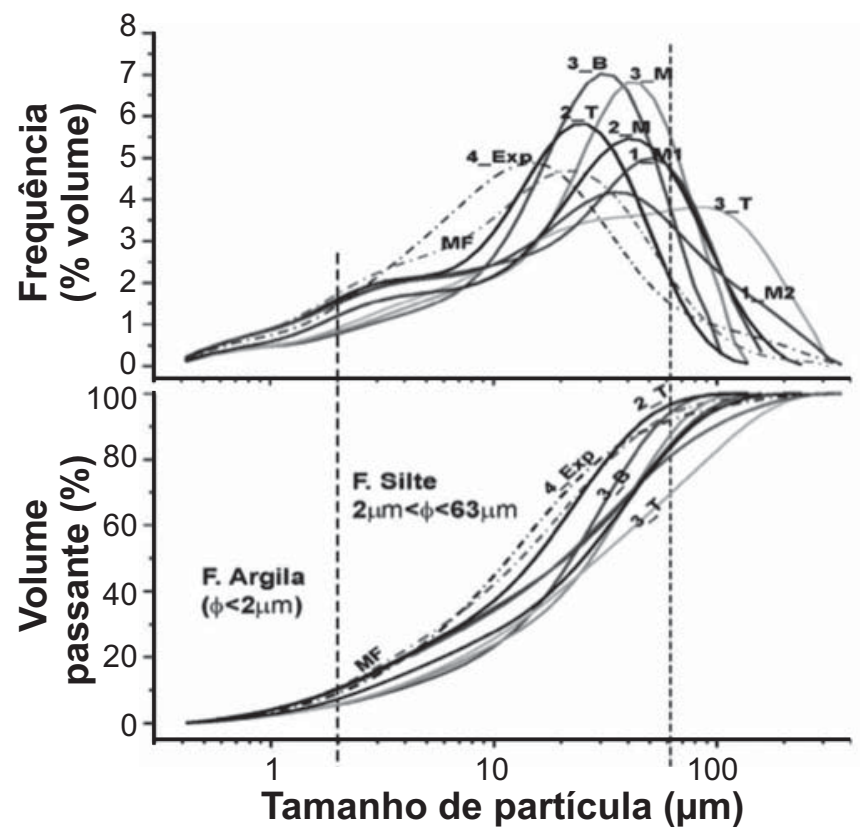

Figura 8: Distribuição granulométrica de moagem das amostras utilizadas na composição de massas.

[Figure 8: Particle size distribution after milling of the samples used in mass composition.]

\section{Caracterização cerâmica}

As argilas mais usadas na fábrica foram caracterizadas quanto às propriedades cerâmicas (Fig. 9) em corpos de prova prensados com $9 \%$ de umidade e, embora sejam processadas por extrusão na fábrica, o comportamento relativo entre as amostras satisfaz os objetivos da pesquisa. Foram prensados corpos de prova das amostras individuais e de formulações de quatro componentes, queimadas a $900{ }^{\circ} \mathrm{C}$ devido ao uso atual em cerâmica estrutural e a $1100^{\circ} \mathrm{C}$ para fins comparativos. A 


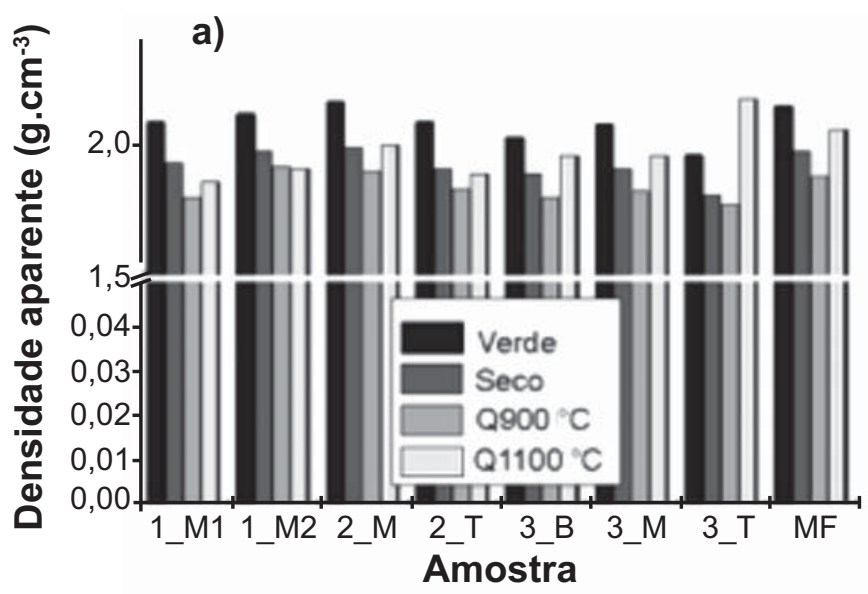

c)

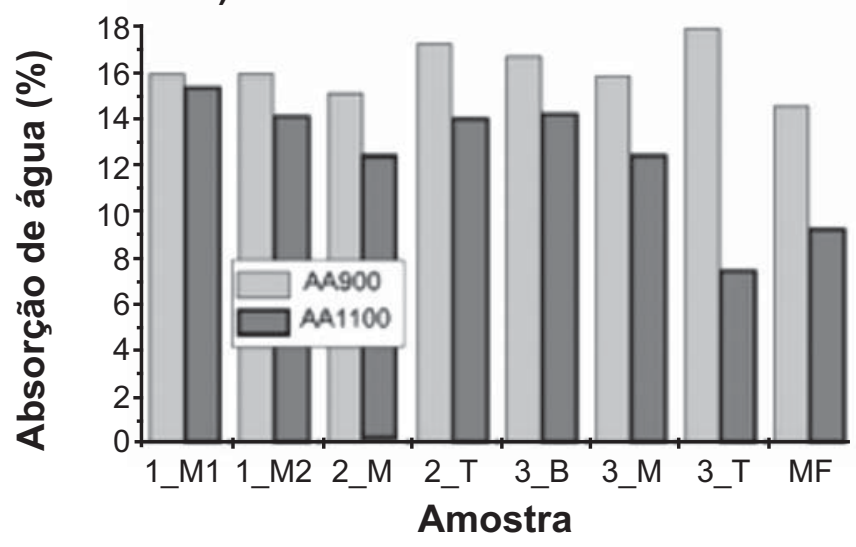

b)

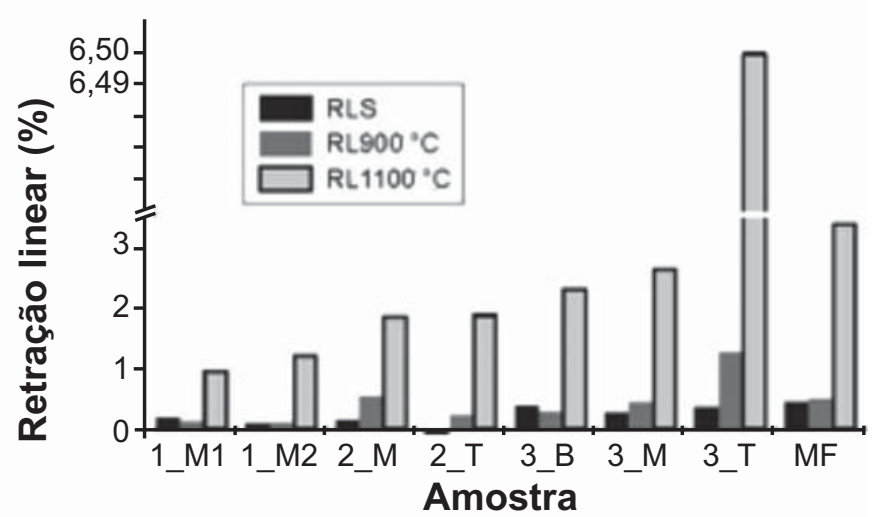

d)

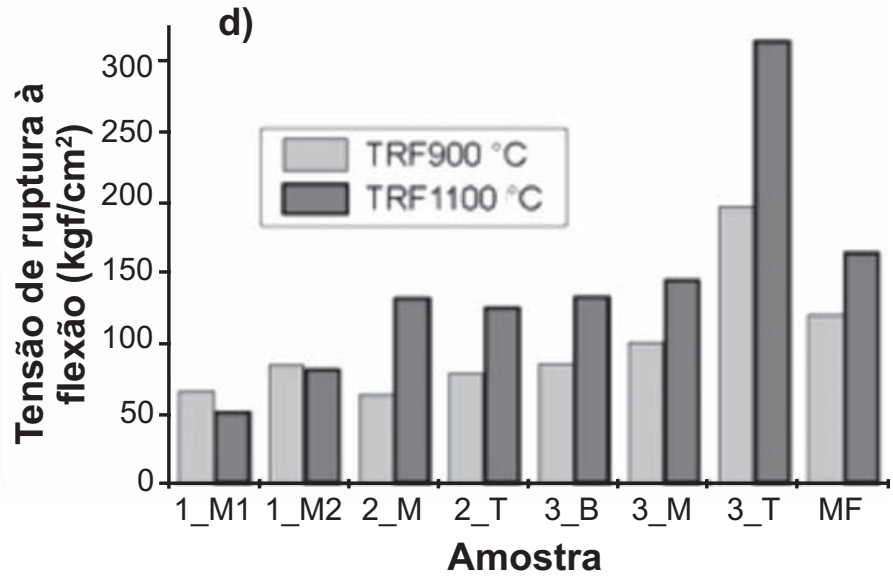

Figura 9: (a) Variação da densidade aparente das amostras verde-seco, seco-Q900 ${ }^{\circ} \mathrm{C}$ e seco-Q1100 ${ }^{\circ} \mathrm{C}$; (b) retração linear de secagem e após queimas a 900 e $1100{ }^{\circ} \mathrm{C}$; (c) absorção de água das peças queimadas e (d) resistência mecânica medida em dispositivo de flexão de três pontos.

[Figure 9: (a) Apparent density variation of green-dry, dry-Q900 ${ }^{\circ} \mathrm{C}$ and $d r y-Q 1100{ }^{\circ} \mathrm{C}$ samples; (b) linear shrinkage after drying and firings at 900 and $1100^{\circ} \mathrm{C}$; (c) water absorption of fired samples and (d) mechanical strength measured in a three point flexure device.]

Fig. 9a mostra a densidade dos corpos de prova das argilas individuais nas diferentes etapas (conformação, secagem e queima), as quais foram usadas em laboratório na preparação das massas cerâmicas. Observa-se a redução contínua da densidade na sequência verde-seco-Q900 ${ }^{\circ} \mathrm{C}$, inicialmente por perda de água e acomodação das partículas (etapa verdeseco) e durante a queima uma nova acomodação como consequência da desestruturação dos argilominerais com liberação de água (pré-sinterização) e reações por migração de íons [3]. Na queima a $1100{ }^{\circ} \mathrm{C}$ ocorre uma maior retração, sendo que a densidade seco-Q1100 aumenta para as amostras das minas 2 e 3 , entretanto para as amostras da mina 1 não houve variação significativa em relação à densidade seco-Q900 indicando deficiência no empacotamento, que afeta o contato entre partículas e portanto as reações, resultando em maior absorção de água e menor resistência mecânica (Figs. 9c e 9d). Por outro lado, a amostra 3T apresenta um aumento significativamente maior, tendo uma distribuição granulométrica mais ampla e mineralogia com menor conteúdo relativo de quartzo (Figs. 6 e 7), como consequência a retração linear foi grande, a absorção de água baixa e a resistência mecânica alta (Figs. 9b, 9c e 9d). Os resultados da resistência mecânica dos corpos de prova (Fig. 9d), nas duas temperaturas de queima, mostram uma sequência inversa à observada na Fig. 4, indicando que a principal causa desta propriedade reside no grau de intemperismo dos estratos argilosos.

\section{Massas preparadas com as amostras de argila}

Os gráficos de consistência são apresentados na Fig. 10 e mostram o comportamento diferenciado das amostras durante a interação com a água. As amostras MF e EXP aparentemente apresentam comportamento semelhante, entretanto a distribuição granulométrica destas difere, uma vez que MF está deslocada para os tamanhos maiores apresentando menor proporção de silte, conforme mostra o gráfico de volume acumulado na parte inferior da Fig. 8. Os feldspatos além de seu tamanho maior só adsorvem água na superfície, motivo pelo qual a amostra 3_M mostra maior tendência à saturação com água (menor inclinação da reta), pois se trata de uma argila com maior teor de feldspatos, maior teor de partículas grossas e cerca de $60 \%$ de fração areia (Fig. 8). Com base nos gráficos de consistência (Fig. 10) e utilizando a regra da alavanca (Fig. 11), foram calculadas diversas combinações 


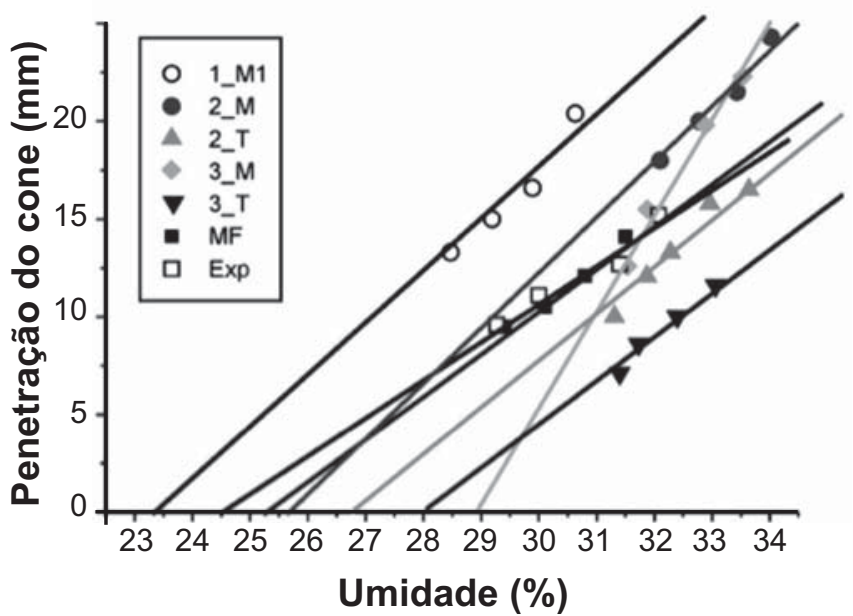

Figura 10: Gráfico de consistência das matérias-primas utilizadas na preparação de massas cerâmicas.

[Figure 10: Consistency chart of the raw materials used in the preparation of ceramic masses.]

Tabela II - Equações das retas obtidas a partir do gráfico de consistência (Fig. 10).

[Table II - Equations of the fitted lines obtained from the consistence chart (Fig. 10).]

\begin{tabular}{ccc}
\hline Amostra & Equação & $\mathrm{R}^{2}$ \\
\hline 1_M1 & $\mathrm{Y}=2,324 \mathrm{x}-52,86$ & 0,999 \\
2_M & $\mathrm{Y}=3,235 \mathrm{x}-84,11$ & 0,972 \\
2_T & $\mathrm{Y}=2,532 \mathrm{x}-68,54$ & 0,960 \\
3_M & $\mathrm{Y}=4,686 \mathrm{x}-134,53$ & 0,975 \\
3_T & $\mathrm{Y}=2,214 \mathrm{x}-61,63$ & 0,999 \\
MF & $\mathrm{Y}=2,188 \mathrm{x}-55,14$ & 0,976 \\
Exp & $\mathrm{Y}=1,991 \mathrm{x}-48,69$ & 0,999 \\
\hline
\end{tabular}

de argilas tendo como referência a massa da fábrica (MF) e a penetração do cone de $2,5 \mathrm{~mm}$, uma vez que os corpos de prova foram obtidos pelo processo via seca e, segundo [8], este valor corresponde aproximadamente ao limite de plasticidade.

A Tabela III mostra as composições ensaiadas e a Tabela IV os resultados cerâmicos obtidos para estas composições, os quais são muito próximos entre si, principalmente a absorção de água. Há um comportamento cerâmico melhor na massa da fábrica por ter sido reprocessada junto com as outras amostras, modificando a distribuição granulométrica obtida na fábrica, o que melhorou a compactação e consequentemente a sinterização a $900{ }^{\circ} \mathrm{C}$. Uma das propriedades cerâmicas indicativas da qualidade dos produtos é a absorção de água que, como mostra a Tabela IV, é muito parecida para todas as formulações preparadas. Os menores valores para Mas4 e Mas5 foram causados pela introdução da argila Exp coletada na porção inferior da mina 4. Esta tem uma distribuição granulométrica parecida com MF (Fig. 8). Dentre as misturas, a Mas4 foi a que mostrou menor resistência mecânica (MRF), em grande parte devido

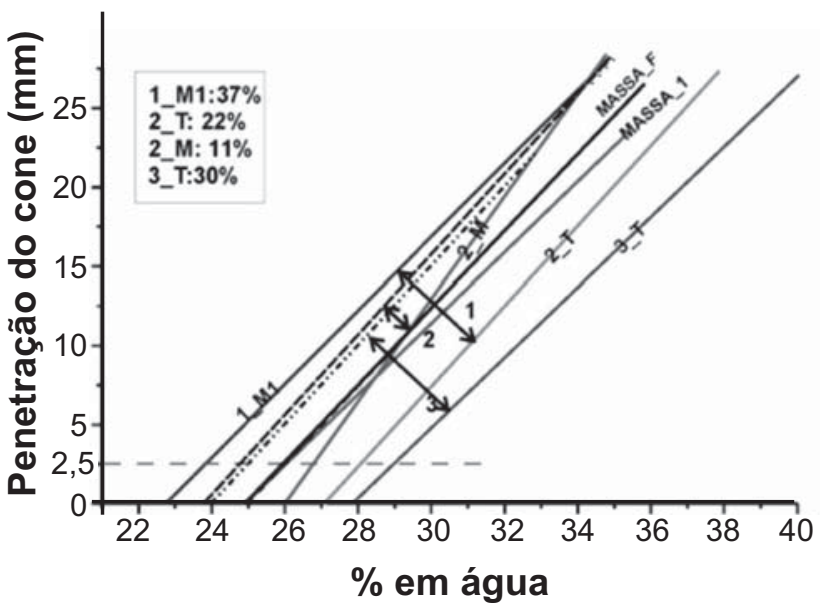

Figura 11: Exemplo de aplicação da regra da alavanca para a massa M1 obtida combinando as equações experimentais das matériasprimas ( $\mathrm{MF}=$ massa da fábrica).

[Figure 11: Example of the lever rule application for the M1 mass obtained by combining the experimental equations of raw materials $(M F=$ factory mass $)$.

à alta concentração da amostra $2 \mathrm{~T}$ (38\%), que contém alto caulim e quartzo (Fig. 5) e baixo potássio (Tabela I e Fig. 3-IV), e individualmente apresentou alta absorção de água por ser uma amostra do topo, submetida a forte intemperismo (Fig. 9c); porém, mesmo assim está dentro dos valores de absorção de água requeridos para blocos cerâmicos $(8 \% \leq$ $\mathrm{AA} \leq 25 \%$ ) [12]. Vale ressaltar que o desvio padrão de MRF é alto devido à precisão do equipamento utilizado. Nesse sentido, a absorção de água é mais confiável para fins de comparação, por outro lado as dimensões e formato dos corpos de prova são diferentes às condições reais.

Para fixar a penetração do cone para aplicação da regra da alavanca deve ser considerada a disponibilidade das matérias-primas e resultados de testes de queima das argilas individuais, pois várias combinações das mesmas argilas podem levar a resultados parecidos, o que é uma vantagem, pois permite a seleção de uma formulação mais conveniente. Cabe ressaltar que os gráficos de consistência informam sobre a etapa de pré-queima e a temperaturas altas, se a intensidade dos processos de formação de fase líquida for significativa, podem ocorrer desvios diferentes do esperado; porém, as proporções podem ser recalculadas a partir dos mesmos gráficos dos materiais componentes, aumentando/ reduzindo fundentes a partir do comportamento de queima das matérias-primas (ou não plastificantes), distribuição granulométrica mais fina (ou grossa) ou selecionando outras matérias-primas. Trata-se de um guia útil para selecionar matérias-primas, controlar as mesmas, já que a composição muda conforme avança a lavra, fazer correções e combinações alternativas, portanto contribuindo para manter a qualidade dos produtos finais.

\section{CONCLUSÕES}

Verificou-se que a análise química pode dar informações 
Tabela III - Composição de massas com argilas do polo cerâmico Tatuí-Sorocaba obtidas a partir dos gráficos de consistência de pastas.

[Table III - Composition of masses with the ceramic clays of Tatui-Sorocaba region obtained from the consistency charts.]

\begin{tabular}{ccccccc}
\hline Argila & $\begin{array}{c}\text { Mas1 } \\
(\%)\end{array}$ & $\begin{array}{c}\text { Mas2_A } \\
(\%)\end{array}$ & $\begin{array}{c}\text { Mas2_B } \\
(\%)\end{array}$ & $\begin{array}{c}\text { Mas3 } \\
(\%)\end{array}$ & $\begin{array}{c}\text { Mas4 } \\
(\%)\end{array}$ & $\begin{array}{c}\text { Mas5 } \\
(\%)\end{array}$ \\
\hline 1_M1 & 37,1 & 23,3 & 13,0 & ---- & 22,0 & 43,5 \\
1_M2 & ---- & 23,3 & 13,0 & 13,9 & 25,0 & ---- \\
2_T & 22,3 & ---- & ---- & 17,6 & 38,0 & ---- \\
2_M & 10,7 & 23,3 & 30,5 & 31,6 & ---- & 25,5 \\
3_T & 29,9 & 30,1 & 43,5 & 36,9 & ---- & 18,0 \\
Exp & ---- & ---- & ---- & ---- & 15,0 & 13,0 \\
\hline
\end{tabular}

Tabela IV - Propriedades cerâmicas das massas preparadas a partir dos gráficos de consistência: Dv - densidade a verde; Ds - densidade seco; $\mathrm{D}_{900}$ - densidade após queima a $900{ }^{\circ} \mathrm{C}$; RLs, retração linear verde-seco; $\mathrm{RL}_{900}{ }^{-}$ retração seco-queimado; $\mathrm{MRF}_{900}$ - módulo de ruptura à flexão das peças queimadas e $\mathrm{AA}$ - absorção de água das peças queimadas.

[Table IV - Ceramic properties of the specimens prepared from consistency charts: Dv - green density; Ds - dry density; $D_{900}$ density after firing at $900^{\circ} \mathrm{C} ; R L$ - green-dry linear shrinkage; $R L_{900}$-dry-fired linear shrinkage; $M R F_{900}$ - modulus of rupture in flexure of fired specimens; and AA - water absorption of fired specimens.]

\begin{tabular}{cccccccc}
\hline & $\begin{array}{c}\mathrm{Dv} \\
\left(\mathrm{g} \cdot \mathrm{cm}^{-3}\right)\end{array}$ & $\begin{array}{c}\mathrm{Ds} \\
\left(\mathrm{g} \cdot \mathrm{cm}^{-3}\right)\end{array}$ & $\begin{array}{c}\mathrm{D}_{900} \\
\left(\mathrm{~g} \cdot \mathrm{cm}^{-3}\right)\end{array}$ & $\begin{array}{c}\mathrm{RLs} \\
(\%)\end{array}$ & $\begin{array}{c}\mathrm{RL}_{900} \\
(\%)\end{array}$ & $\begin{array}{c}\mathrm{MRF}_{900} \\
\left(\mathrm{kgf}_{\mathrm{cm}}-\mathrm{cm}^{-2}\right)\end{array}$ & $\begin{array}{c}\mathrm{AA}_{900} \\
(\%)\end{array}$ \\
\hline Mas1 & $2,04 \pm 0,01$ & $1,89 \pm 0,01$ & $1,89 \pm 0,02$ & $0,22 \pm 0,07$ & $0,50 \pm 0,03$ & $160 \pm 14$ & $17,2 \pm 0,1$ \\
Mas2A & $2,03 \pm 0,02$ & $1,90 \pm 0,01$ & $1,87 \pm 0,01$ & $0,23 \pm 0,01$ & $0,46 \pm 0,02$ & $152 \pm 10$ & $17,1 \pm 0,1$ \\
Mas2B & $2,00 \pm 0,01$ & $1,86 \pm 0,02$ & $1,83 \pm 0,02$ & $0,25 \pm 0,01$ & $0,60 \pm 0,01$ & $180 \pm 18$ & $17,6 \pm 0,2$ \\
Mas3 & $2,03 \pm 0,02$ & $1,88 \pm 0,01$ & $1,83 \pm 0,01$ & $0,26 \pm 0,03$ & $0,65 \pm 0,02$ & $184 \pm 8$ & $17,1 \pm 0,1$ \\
Mas4 & $2,14 \pm 0,01$ & $1,93 \pm 0,01$ & $1,86 \pm 0,02$ & $0,25 \pm 0,09$ & $0,25 \pm 0,09$ & $120 \pm 18$ & $16,2 \pm 0,2$ \\
Mas5 & $2,07 \pm 0,02$ & $1,92 \pm 0,02$ & $1,85 \pm 0,02$ & $0,33 \pm 0,02$ & $0,39 \pm 0,02$ & $196 \pm 14$ & $16,3 \pm 0,3$ \\
MF & $2,15 \pm 0,02$ & $1,98 \pm 0,05$ & $1,88 \pm 0,05$ & $0,47 \pm 0,03$ & $0,53 \pm 0,03$ & $242 \pm 30$ & $14,6 \pm 0,2$ \\
\hline
\end{tabular}

sobre as características básicas que distinguem as duas aplicações (estrutural e revestimentos), da mesma forma a mineralogia pode explicar a distribuição granulométrica de moagem, aspecto importante no empacotamento das partículas durante a conformação das peças. Os resultados da resistência mecânica dos corpos de prova, nas duas temperaturas de queima, mostram uma relação inversa com o grau de intemperismo das argilas, mostrando a importância da caracterização das matérias-primas cerâmicas para o aproveitamento adequado das argilas industriais, trazendo benefícios tanto para o meio ambiente como econômicos, uma vez que diferentes composições podem levar a resultados semelhantes, contribuindo para a eficiência da lavra e da fábrica. Em função das matérias-primas disponíveis, é possível formular massas com base nos resultados das relações argila-água, onde o aparelho de Vicat Cone mostrou-se eficiente, principalmente por sua praticidade, e pode indicar caminhos alternativos de tratamento da matériaprima ou orientar a troca de componentes. A combinação de matérias-primas estudadas com base nos gráficos de consistência gerou produtos com características próximas à amostra de referência. $\mathrm{O}$ fato dos valores de absorção de água e propriedades relacionadas serem inferiores à massa da fábrica se deve, principalmente, ao tratamento dado no labratório, o qual modificou a distribuição granulométrica gerando maior quantidade de finos e aumentando os contatos intergranulares que melhoraram a sinterização. De qualquer forma, o processo de desagregação das partículas na fábrica não é o mesmo do laboratório; por outro lado, a preparação de uma composição igual à da fábrica é difícil, pois em laboratório as quantidades processadas são pequenas, assim como o ambiente interno do forno e o material da mina 4, utilizado industrialmente, não foi considerado integralmente; entretanto, os ensaios e análise deste trabalho consideraram o comportamento relativo entre as amostras, que certamente será mantido em outras condições dentro de certos limites de tolerância. O método para formular massas cerâmicas depende do comportamento das partículas antes da queima, porém a baixas temperaturas como $900{ }^{\circ} \mathrm{C}$ as variações são pequenas, sendo que na obtenção dos produtos certificados deste tipo deve-se trabalhar com uma boa margem de segurança para se adequar às respectivas normas, além dos 
limites de tolerância serem maiores que para revestimentos. Desta forma, considera-se que os procedimentos testados constituem uma excelente ferramenta de controle de matérias-primas e, consequentemente, de produtos.

\section{REFERÊNCIAS}

[1] P. Souza Santos, Tecnologia de Argilas, 2a Ed., Edgard Blücher, S. Paulo (1989) p. 78.

[2] M. Cabral Jr., J.F.M. Motta, N. Serra, S. Machado, L.C. Tanno, A. Sintoni, G. Cuchieratto, Assessoria TécnicoGerencial para Implantação de um Polo Cerâmico no Estado da Bahia, IPT, S. Paulo (2002).

[3] L.H. van Vlack, Propriedades dos Materiais Cerâmicos, Edgard Blücher, S. Paulo (1973) p. 82, 242.

[4] J.S. Reed, Principles of Ceramics Processing, $2^{\text {nd }}$ Ed., John Wiley \& Sons, New York, USA (1995) p. 99, 596-598. [5] ACME Labs, Acme Analytical Laboratories (Vancouver) 1020 Cordova St. East, Vancouver, BC, Canada, http:// www.acmelab.com.

[6] SACMI, "Prodotti greificati: gres rosso". In Dalla tecnologia Alla machine ai forni per la piastela Sacmi: note tecnologiche sulla fabricazione delle piastrelle ceramiche, Forli 1 (1986).
[7] Associação Brasileira de Normas Técnicas - ABNT, "Placas cerâmicas para revestimentos: especificação e métodos de ensaios: 13818”, Rio de Janeiro (1997) 78p.

[8] J.M.M. Vaillant, "Cone de penetração adaptado para determinação da plasticidade das argilas", in Anais 52 Congresso Brasileiro de Cerâmica, Associação Brasileira de Cerâmica, Florianópolis, SC (2008) p. 1-11.

[9] M.M.T. Moreno, A. Zanardo, R.R. Rocha, C.D. Roveri, "Matéria prima da Formação Corumbataí na região do polo cerâmico de Santa Gertrudes, SP, com características naturais para fabricação de argila expandida", Cerâmica 58 (2012) 342-348.

[10] H.R. Rollinson, Using Geochemical Data: Evaluation, Presentation, Interpretation, Longman Publishers, Singapore (1995) p. 54.

[11] M.M.T. Moreno, R.R. Rocha, L.H. Godoy, "Major elements geochemistry of sedimentary rocks from Corumbataí Formation, Santa Gertrudes Ceramic pole, S. Paulo, Brazil", Geomaterials 04, 01 (2014) 11-17.

[12] Associação Brasileira de Normas Técnicas - ABNT, "Bloco cerâmico para alvenaria: NBR 7171/1992", Rio de Janeiro (1983) p. 7.

(Rec. 17/07/2015, Rev. 27/08/2015, 23/09/2015, Ac. 10/10/2015) 